\title{
Role of blood and blood components transfusion in obstetric emergencies
}

\author{
Parul Vaid', Bhavuk Kapoor ${ }^{2 *}$, Mayank Kapoor³ ${ }^{3}$ Bharat B. Kapoor ${ }^{4}$
}

\author{
${ }^{1}$ Department of Obstetrics and Gynecology, SMGS Hospital GMC Jammu, Jammu and Kashmir, India \\ ${ }^{2}$ Department of Neurosurgery, GMC Jammu, Jammu and Kashmir, India \\ ${ }^{3}$ Department of Medicine, AIIMS, Rishikesh, Uttarakhand, India \\ ${ }^{4}$ Department of Anaesthesia and ICU, GMC Jammu, Jammu and Kashmir, India
}

Received: 06 March 2020

Accepted: 12 March 2020

\section{*Correspondence:}

Dr. Bhavuk Kapoor,

E-mail: kapoorbhavuk@yahoo.in

Copyright: ( ) the author(s), publisher and licensee Medip Academy. This is an open-access article distributed under the terms of the Creative Commons Attribution Non-Commercial License, which permits unrestricted non-commercial use, distribution, and reproduction in any medium, provided the original work is properly cited.

\begin{abstract}
Background: Common obstetric emergencies require blood and blood components transfusion. The use of blood and its components has become a lifesaving strategy in management of obstetric haemorrhage. This study was aimed to know the prevalence, indications and adverse reactions of blood and its components transfusion.

Methods: A review of 405 patients of obstetric emergencies requiring blood and its component transfusion was done. Results: Prevalence of blood and blood components transfusion in obstetric emergencies in one-year period was $18.4 \%$. Mostly women who received blood transfusions were multiparous $(50.12 \%)$ and belonged to rural areas $(62 \%)$. Anemia is a risk factor for obstetric emergencies and the mean pre transfusion hemoglobin \pm SD was $8.04 \pm 1.38(\mathrm{~g} / \mathrm{dl})$. Obstetric hemorrhage $(68.6 \%)$ was the most common indication for transfusion and packed red cells were most commonly (54.07\%) transfused. The overall percentage of adverse reactions seen during transfusion was $1.95 \%$.

Conclusions: The present study reinforces the importance of appropriate use of blood and its components in obstetric emergencies. Appropriate use of blood components avoids many of the hazards associated with use of whole blood. All blood components should be made available at peripheral hospitals as most of the patients require specific blood component and they are referred to tertiary care centre in emergencies which can be avoided.
\end{abstract}

Keywords: Blood component transfusion, Blood transfusion, Obstetric emergencies, Transfusion adverse reactions

\section{INTRODUCTION}

Blood transfusion services are vital to maternal health because obstetric haemorrhage has been the foremost cause of maternal mortality in India. Pregnancy although a physiological state, can turn pathological suddenly and unexpectedly if not cared for.

Common obstetric emergencies which require blood and blood components transfusion are acute blood loss in first half of pregnancy due to conditions like complications of abortions, ectopic pregnancy rupture and vesicular mole.
In later half of pregnancy, there can be haemorrhage due to placenta previa or accidental haemorrhage. During labour, women may present with severe anemia and may develop third stage haemorrhage or other complications resulting in severe blood loss and sudden deterioration in general condition can occur.

Immediate and rapid replacement of sufficient and safe blood and its components becomes essential to save the lives of women. The use of blood and its components has become a lifesaving strategy in management of obstetric haemorrhage in general and PPH in particular. 
Anemia of pregnancy is defined as haemoglobin concentration $<11 \mathrm{~g} / \mathrm{dl}$ in $1 \mathrm{st}$ and 3rd trimester and below $10.5 \mathrm{~g} / \mathrm{dl}$ in 2nd trimester. Early correction of anemia avoids the need for transfusion and reduces maternal mortality. The decision of transfusion should be made on both clinical and haematological grounds. ${ }^{1}$

\section{WHO classification of anemia}

- $\quad$ Mild: $10-10.9 \mathrm{~g} / \mathrm{dl}$

- Moderate: 7-9.9 g/dl

- Severe: 4-6.9 g/dl

- Very severe: $<4 \mathrm{~g} / \mathrm{dl}$.

Transfusion is almost always indicated when $\mathrm{Hb}$ is less than $7 \mathrm{~g} / \mathrm{dl}$ to reduce the rate of maternal morbidity and mortality. ${ }^{2}$ In India the prevalence of anemia is around $65-75 \% .^{3}$

Obstetric haemorrhage is defined as any blood loss associated with pregnancy or parturition which may be revealed or concealed and is likely to endanger life. Patients usually present with shock which requires urgent blood and its components transfusion. According to sample registration survey (1997-2003), postpartum haemorrhage accounts for nearly $38 \%$ of all maternal deaths. $^{4}$

The management of obstetric haemorrhage is more challenging than haemorrhage in non-pregnant patients because of hypervolemia of pregnancy by approximately $50 \%$. Signs of hypovolemia occur relatively late because of physiological changes in pregnancy. The extent of intravascular volume deficit is not reflected by visual estimates of vaginal bleeding. ${ }^{5}$

Role of blood transfusion in acute haemorrhage is to maintain tissue oxygenation and reversal or prevention of coagulopathy using appropriate blood component.

Blood and blood components that can be used:

- $\quad$ RBC'S can be transfused either as whole blood or as packed red cells. Packed red cells are the one and only blood product that provides oxygen carrying capacity and are one of the most appropriate therapy for patients who require red blood cells due to haemorrhage

- Fresh frozen plasma: FFP's should be given for coagulation abnormalities, micro- vascular bleeding when PT and PTI are > 1.5 times the mid-range normal reference values

- Platelets: Obstetrical patients with micro-vascular bleeding often require platelet transfusions when platelet count $<50,000 / \mathrm{mm}^{3}$

- Cryoprecipitate: Cryoprecipitate is extracted from thawing FFP's slowly and is rich in fibrinogen, fibronectin, factor 13, factor 8 and Von Willebrand's factor. These precipitates can be transfused immediately within 6 hours after thawing

- Leucocyte depleted blood: Leukoreduction is the removal of white blood cells from the blood or blood components supplied for blood transfusion. Leucocyte removal from blood components is known to prevent or at least delay leucocyte mediated adverse reactions.

Worldwide more than half a million women die each year during childbirth or in postpartum period. Because of unpredictable nature of postpartum bleeding, blood transfusion is recognized as one of the eighth essential components of comprehensive emergency obstetric care, which has been shown to reduce rates of maternal mortality. ${ }^{6}$

The appropriate and rational use of blood and its components is essential for ensuring availability for the needy as well as preventing risk of transfusion transmitted diseases and transfusion reactions like allergic reactions, acute immune haemolytic reaction, delayed haemolytic reactions etc.

Rational use means providing the right blood or its components in the right quantity, to the right person and at the right time bridging demand and supply gap. Every year, millions of people are exposed to avoidable, lifethreatening risks through the transfusion of unsafe blood.

In developing countries like India efforts should be done to make blood transfusion services well maintained and quickly available to reduce maternal morbidity from haemorrhage and thus decrease the incidence of maternal mortality.

Because of increasing number of patients requiring blood transfusions due to obstetric emergencies and at the same time adverse reactions encountered, this study is aimed to know the prevalence, indications and adverse reactions of blood and its components transfusion in our set up at postgraduate department of obstetrics and gynecology, S.M.G.S Hospital, Government Medical College, Jammu, Jammu and Kashmir, India

\section{METHODS}

All patients requiring blood transfusions due to obstetric emergencies at postgraduate department of obstetrics and gynecology, S.M.G.S Hospital, Government Medical College, Jammu, Jammu and Kashmir, India were included in the study over a period of one year from November 2017 to October 2018.

\section{Inclusion criteria}

- All patients requiring blood and its components transfusion in the antepartum, intrapartum and postpartum period due to any obstetric emergency like ectopic pregnancy, abortions, antepartum 
hemorrhage, postpartum hemorrhage, severe anemia with features of cardiac failure, or any other obstetric emergency requiring blood and its components transfusion were included in the study.

\section{Exclusion criteria}

- All obstetric patients requiring planned blood and blood components transfusions.

After applying inclusion and exclusion criteria, history of patients regarding the underlying cause was taken. General physical examination including vitals, systemic examination, per abdomen and per vaginum examination was done. Investigations particularly blood grouping and pre transfusion hemoglobin at the time of admission was noted.

Study made a record of number of transfusions, type of transfusion, indication of transfusion, any adverse reaction due to transfusion and post transfusion hemoglobin.

\section{Statistical analysis}

At the end of the study, statistical calculations were performed using the SPSS 16.0 software. Student's t-test was used for comparison of mean values and $\mathrm{p}$ value < 0.05 was considered as statistically significant. The present study has been carried out with the objective of assessing the prevalence of blood and blood components transfusion among antenatal and postnatal patients with obstetric emergencies, to study the indications of transfusion among these patients and to study the adverse effects of blood and blood components transfusion in these patients. A total number of 405 patients were included in the study.

\section{RESULTS}

A total number of 405 patients were enrolled in the study with a mean age of $27.7 \pm 3.68$ years and with majority of them belonging to rural areas $(61.98 \%)$.

Table 1: Parity status.

\begin{tabular}{|ll|l|}
\hline Parity & No. of patients & Percentage \\
\hline P0 & 80 & $19.75 \%$ \\
\hline P1 & 122 & $30.12 \%$ \\
\hline$\geq$ P2 & 203 & $50.12 \%$ \\
\hline
\end{tabular}

Majority of the patients were un-booked (69.14\%).

Details on Parity status and pre-transfusion haemoglobin levels are in Table 1 and Table 2. Majority of the patients $(50.12 \%)$ were multiparous $(\geq \mathrm{P} 2)$ and had pre-transfusion mean haemoglobin of $8.04 \pm 1.38 \mathrm{~g} / \mathrm{dl}$.

Mean post-transfusion haemoglobin was $9.11 \pm 0.61 \mathrm{~g} / \mathrm{dl}$.
Table 2: Pre-transfusion hemoglobin.

\begin{tabular}{|lll|}
\hline Hemoglobin $($ g/dl) & No. of patients & Percentage \\
\hline$<7.0$ & 121 & $29.88 \%$ \\
\hline $7.0-9.9$ & 248 & $61.23 \%$ \\
\hline$\geq 10.0$ & 36 & $8.89 \%$ \\
\hline Mean haemoglobin \pm SD & $8.04 \pm 1.38$ & \\
\hline
\end{tabular}

Most common indication of blood transfusion was early trimester haemorrhage with ruptured ectopic being the most common etiology (Figure 1).

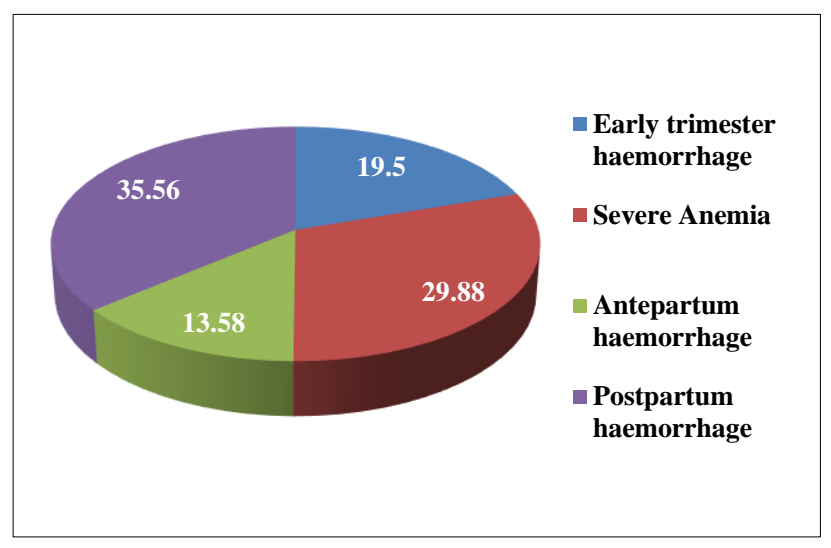

Figure 1: Indications of blood transfusion.

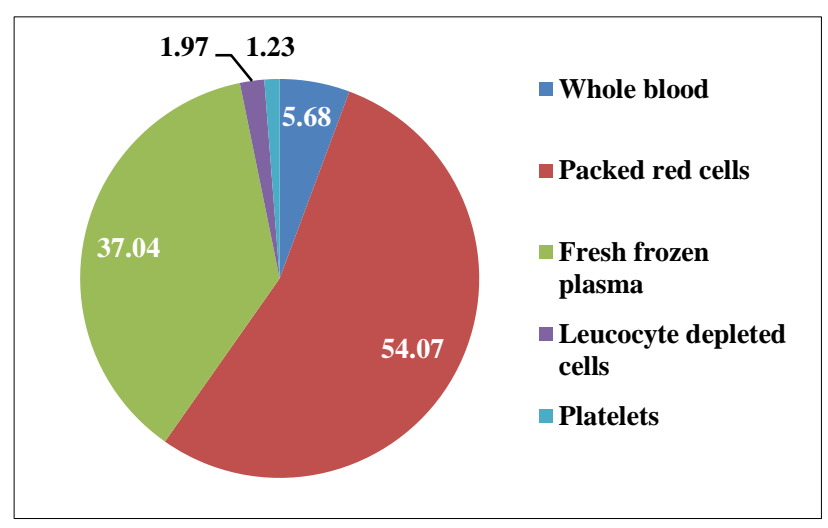

Figure 2: Type of blood and blood components transfusion.

Packed red cells were the most common type (54\%) of blood product used for transfusion (Figure 2).

Most of the patients $(26.17 \%)$ received at least 2 units of transfusion.

The adverse reactions of blood transfusions were seen in $1.95 \%$ of total patients. Shivering and fever $(0.74 \%)$ was the most common adverse reaction seen.

\section{DISCUSSION}

Obstetric emergencies can occur suddenly and unexpectedly. These can be life threatening to mother, fetus or both, bleeding can be catastrophic and timely 
intervention is important. The World Health Organization estimates that at least $88-98 \%$ of maternal deaths can be averted with timely access to existing emergency obstetric care using effective and efficient referral system. Blood transfusion remains a life-saving practice to millions of women annually; it is an adjunct to good obstetric care with obstetric hemorrhage and severe anemia being some of the most common indications. Obstetric emergencies associated with urgent need for blood may grow direr if not managed effectively.

This study was conducted keeping in view the requirement of blood and blood components transfusion in obstetric emergencies. All patients requiring blood and its components transfusion in obstetric emergencies were included in the study.

The prevalence of blood and blood components transfusion in obstetric emergencies was $18.4 \%$ in this study. In another study, incidence of blood and its components transfusion was found to be $14.4 \% .7$

The maximum number of patients 197 (48.6\%) were in the age group of 26-30 years in this study, which was comparable to the results found in a study by Chawla $\mathrm{S}$ et al, in India where majority of patients receiving blood transfusion were in the age group of 21-30 years and in the study conducted by Fazal $\mathrm{S}$ et al, in Kerala where maximum number of patients were in the age group of 20-29 years. ${ }^{8,9}$ Also in another study, it was reported that the risk of blood transfusion was more in extremes of age. $^{10}$

While observing the parity status we found that $50.12 \%$ of women who received blood transfusions were multiparous with at least 2 previous viable births. In a study by Mahalakshmi G et al, $42.3 \%$ of women were multiparous and had at least 2 previous viable births. ${ }^{7}$ Bindal $\mathbf{J}$ et al, also found that maximum number of patients $(50 \%)$ in the study were multigravida. ${ }^{11}$ Also in a study by Chowdhury $\mathrm{F}$ et al, done in Bangladesh, $68.3 \%$ of women were multiparous. ${ }^{12}$ So, multiparity as such is a risk factor and these patients require utmost care in their management.

In this study the majority of patients $(62 \%)$ were resident of rural areas while $38 \%$ patients were resident of urban areas. In another study, it was found that $57 \%$ of patients were resident of rural areas and $43 \%$ of patients were resident of urban areas. ${ }^{13}$ This indicates that urbanization and availability of proper services and education can reduce the requirement of blood transfusion in obstetric emergencies as patients can access medical care early.

Booked patients were regarded as those who received antenatal care at the hospital while un-booked patients were those who did not access antenatal care at all or received care at health centers other than the hospital. In this study, majority of the patients who received blood and its components belonged to un-booked cases (69\%).
This was in accordance with another study, where unbooked cases receiving blood transfusion were $73 \% .^{7}$ This can be attributed to the fact that majority of the patients with obstetric emergencies were referred to the hospital from periphery and some of them have not maintained any antenatal record. This indicates the importance of regular antenatal visits in providing iron prophylaxis which prevents anemia of pregnancy, helps in early detection and treatment of anemia by providing both oral or parental iron therapy and also screening for high risk cases can be done at an earlier stage so that blood transfusion and subsequent complications of blood transfusion can be avoided. This also indicates that previously booked cases had lesser incidence of presenting with obstetric emergency hence requiring lesser number of transfusions.

Mean pre transfusion hemoglobin \pm SD in this study was $8.04 \pm 1.38(\mathrm{~g} / \mathrm{dl})$. So, anemia as such is a risk factor for obstetric emergencies and patients should be screened for anemia during antenatal check-ups. This was similar to study by Singh RK et al, where mean pre- transfusion $\mathrm{Hb}$ was $7.84 \mathrm{~g} / \mathrm{dl} .{ }^{14}$ Also in another study it was seen that majority of patients $46.83 \%$ were recorded in hemoglobin range of $7-9(\mathrm{~g} / \mathrm{dl}) .^{12}$

Most of the patients $(68.6 \%)$ in this study required blood and blood component transfusion because of obstetric hemorrhage where PPH $(35.56 \%)$ was the most common indication. This was also seen in another study, where $70 \%$ patients admitted as obstetrical emergencies, required blood and its components transfusion due to obstetric hemorrhage and $30 \%$ required blood and its components transfusion due to severe anaemia. ${ }^{15}$ In another study done, $81 \%$ of blood transfusions were associated with obstetric haemorrhage. ${ }^{16}$ The findings in this study are also in accordance with those reported by Chhabra et al, where obstetric hemorrhage and severe anemia were the major indications of blood and its components transfusion in obstetric emergency cases. ${ }^{17}$

The various causes of obstetric hemorrhage were divided into early trimester hemorrhage, antepartum hemorrhage (APH) and postpartum hemorrhage (PPH) for the purpose of the study. Overall PPH (35.5\%) was the most common indication of blood and blood components transfusion in this study. Next common cause was severe anaemia $(29.8 \%)$ in antepartum and postpartum patients. These findings were also seen in study by Patel VP et al, where PPH accounted for $36 \%$ of the cases and severe anemia accounted for $34 \%$ of the cases. ${ }^{15}$ This can be attributed to the fact that the hospital is a tertiary care centre where patients with obstetric emergencies are mostly referred from peripheral hospitals. Anemia can be managed at peripheral hospitals but all cases of $\mathrm{PPH}$ with shock are mostly referred to this centre for further management because of unavailability of blood components at peripheral hospitals. Therefore, in this study PPH has surpassed anemia as most common cause of blood and its components transfusion in obstetric emergencies. 
Majority of the patients received multiple transfusions in this study with $26.17 \%$ of the patients receiving at least 2 units of blood and its components transfusion. In a study by Bangal VB et al, it was seen that maximum 2 units were transfused in $37.74 \%$ of patients followed by 3 units in $25.96 \%$ of patients. $^{18}$

The overall percentage of adverse reactions seen during transfusion in this study was $1.95 \%$ with shivering and fever being the most common $(0.74 \%)$. In a review article on rational use of blood and its components in obstetricsgynecological practice it was given that $1 \%$ of all the transfusions lead to some adverse reaction. ${ }^{17}$

\section{CONCLUSION}

This study showed that severe obstetric haemorrhage is a relatively frequent complication. The present study reinforces the importance of appropriate use of blood and its components in obstetric emergencies. Blood transfusion is need of the hour in acute blood loss as this not only prevents mortalities but also decrease morbidities associated with it. It is indispensable for saving lives of mothers who need comprehensive emergency obstetric care services because of pregnancy related haemorrhage, severe anemia or abortions.

As it is rightly said that prevention is better than cure, thus during nine months period, obstetrician must encourage pregnant women to maintain their haemoglobin level in normal range. Moderate anaemia may be treated with intravenous iron therapy in third trimester, so that haemoglobin rise takes place over few weeks' time. Appropriate use of blood components avoids many of the hazards associated with use of whole blood. Particular emphasis should be placed on active management of third stage of labour to prevent avoidable morbidities such as PPH, retained products of conception, vaginal lacerations etc. which require blood and its components transfusions. All blood components should be made available at peripheral hospitals as most of the patients require specific blood component and they are referred to tertiary care centre in emergencies which can be avoided.

\section{ACKNOWLEDGMENTS}

The authors acknowledge the support of their family members. The authors would like to thank all the patients as well.

\section{Funding: No funding sources}

Conflict of interest: None declared

Ethical approval: The study was approved by the Institutional Ethics Committee

\section{REFERENCES}

1. British Committee for Standards in Hematology. Blood Transfusion Task Force. Guidelines for the clinical use of red cell transfusions. Br J Haematol. 2001;113:24-31.

2. Reveiz L, Gyte GM, Cuervo LG. Treatments for iron-deficiency anemia in pregnancy. Cochrane Database Syst Rev. 2007;4:CD003094.

3. DeMayer EM, Tegman A. Prevalence of anaemia in the world. World Health Organ Qlty. 1998;38:30216.

4. Registrar General of India. Sample registration survey. Maternal mortality in India: 1997-2003, trends, causes and risk factors. In: Registrar General of India, eds. A Survey. New Delhi: Registrar General of India; 2006:29.

5. Rock JA, Thomson JD. Te Linde's operative gynecology. $8^{\text {th }}$ ed. Philadelphia: Lippincott-Raven; 1997:245-61.

6. Chandy BK. WHO fact sheet. Kuwait Med J. 2007;39(3):298-302.

7. Mahalakshmi G, Nimma W, Mounika K, Amulya G. The study of peripartum transfusions of blood and its products in a tertiary hospital. IOSR J Dent Med Sci. 2016;15(5):23-7.

8. Chawla S, Bal MHK, Vardhan BS, Jose CT, Sahoo I. Blood transfusion practices in obstetrics: our experience. J Obstet Gynecol India. 2018;68(3):2047.

9. Fazal S, Poornima AP. A study on transfusion practice in obstetric hemorrhage in a tertiary care centre. Glob J Transfus Med. 2018;3:41-5.

10. Jou HJ, Hung HW, YAN YH, Wu SC. Risk factors for blood transfusion in singleton pregnancy deliveries in Taiwan. Int $\mathbf{J}$ Gynaecol Obstet. 2012;117(2):124-7.

11. Bindal J, Agrawal N, Sharma DC. Over view of referred obstetric patients and their outcome in tertiary care Hospital. JMSCR. 2017;5(5):22485-91.

12. Chowdhury F, Akhter S, Islam A, Rayend J, Begum $\mathrm{N}$, Begum F. Evaluation of blood transfusion practices in obstetrics and gynaecology in a tertiary hospital in Bangladesh. J Bangladesh Coll Phys Surg. 2016;34:9-14.

13. Lawani OL, Lyoke CA, Onyebuchi AK. Blood transfusion trends in obstetrics at the Federal Teaching Hospital in Abakaliki, South- East Nigeria.Int J Womens Health. 2013;5:407-12.

14. Singh RK, Anne S, Ravindran PS. Changing trends of Blood transfusion requirement in obstetrics and gynaecology. Int J Reprod Contracept Obstetric Gynecol. 2018;7(5):2018-22.

15. Patel VP, Patel RV, Shah PT, Patel CK. Study of role of blood transfusion in obstetric emergencies. Int J Reprod Contracept Obstet Gynecol. 2014;3(4):1002-5.

16. Patterson JA, Robers CL, Bowen JR, Irving DO, Isbister JP, Morris JM, et al. Blood transfusion during pregnancy, birth, and the postnatal period. Obstet Gynecol. 2014;123(1):126-33.

17. Chhabra S, Namgyal A. Rationale use of blood and its components in obstetric-gynecological practice. J Mahatma Gandhi Institute Med Sci. 2014;19(2):93-9. 
18. Bangal VB, Gavhane SP, Aher KH, Bhavsar DK, Verma PR, Gagare SD. Pattern of utilization of blood and blood components in obstetrics at tertiary care hospital. Int J Reprod Contracept Obstet Gynecol. 2017;6(10):4671-6.
Cite this article as: Vaid P, Kapoor B, Kapoor M, Kapoor BB. Role of blood and blood components transfusion in obstetric emergencies. Int J Reprod Contracept Obstet Gynecol 2020;9:2029-34. 